\title{
The 2010 Paul Janssen Award recognizes achievement in AIDS research
}

n September 8, Johnson \& Johnson awarded the 2010 Dr. Paul Janssen Award for Biomedical Research to Anthony Fauci, director of the National Institute of Allergy and Infectious Diseases at the NIH, and Erik De Clercq, professor emeritus at the Rega Institute for Medical Research in Belgium (Figure 1), in recognition of their work on HIV and AIDS. Named for physician and chemist Paul Janssen, known affectionately as Dr. Paul, the award honors active scientists who have made contributions to the improvement of human health. The JCI recently spoke to Fauci and De Clercq about the award, their careers, and the future of AIDS research.

JCI: How did you decide to focus your careers on virology?

Fauci: I started off my career trained as an infectious disease person studying all aspects of infection: bacteria, viruses, parasites. My fundamental research focus was in the area of immunology ... When HIV came around, I turned around the direction of my career to begin exclusively studying HIV. I de facto made myself a virologist who bridges the back and forth between the host response - namely the immune system - and the virus itself.

De Clercq: As a student I was originally fascinated by the biosynthesis of the steroid hormones, until I was spotted by Professor of Microbiology Piet De Somer, who invited me to work with him on the "chemistry of viruses." As it turned out, he wanted me to work on interferon ... He thought interferon would be the panacea for treating all virus infections, just like penicillin was thought of for bacterial infections, and he wanted me to follow him in this belief.

JCI: How do you think the AIDS epidemic changed infectious disease research?

Fauci: Some decades ago, there had been the false impression that the era of infectious diseases was over. When I came down to the NIH in 1968 after my medical residency for training in infectious diseases, some pundits said, "This is really a specialty that's on its way out because we've now handled all of the infectious diseases with vaccines and antivirals, and antibiotics, and you should be concentrating on chronic diseases like cardiovascular disease and cancer." But they were only thinking in terms

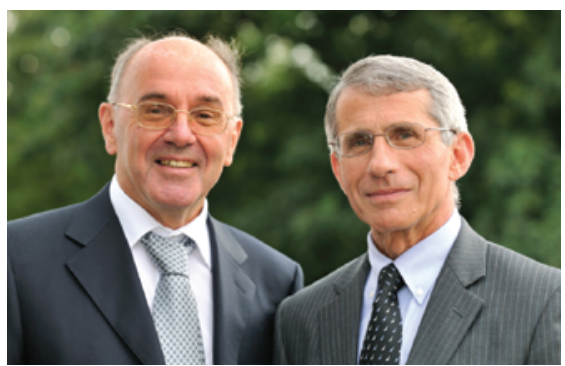

Figure 1

Erik De Clercq (left) and Anthony Fauci.

of decades, instead of thinking in terms of many decades or a century. There is a list of emerging and reemerging infections that have an enormous impact on global health. What AIDS has told us is that essentially overnight, you can have the emergence of an infectious disease that has absolutely devastating consequences on global health.

De Clercq: AIDS really ignited the search for antiviral agents blocking the replication of the causative agent of the infection. In 25 years this had led to 25 compounds that have been formally approved by the U.S. FDA for the treatment of AIDS. That set the scene for combating other important viral infections such as human hepatitis $B$ (HBV) and human hepatitis $\mathrm{C}(\mathrm{HCV})$.

JCI: What do you think are some of the outstanding questions in AIDS research?

De Clercq: Two questions remain outstanding. First, how can we make the compounds that have proven to be so successful in the treatment of AIDS globally available so that mankind at large could profit? Second, while awaiting the advent of an effective vaccine, what can we expect from a chemoprophylactic approach? High hopes are vested in the use of the appropriate antiHIV agents such as a vaginal microbicide or, even better, a daily oral pill.

JCI: How close are we to a working AIDS vaccine?

Fauci: It would be folly for me or anyone else to give a particular date and say we're 3 years away, 5 years away, 10 years away. The fact is we have been unsuccessful in the development of a vaccine for about 25 years. But last year there was a modest, but nonetheless quite clear positive signal for protection from a trial that was conducted in Thailand in individuals that were of relatively low risk... People in the field of AIDS vaccinology are very encouraged that finally, we see some light at the end of the tunnel. That tunnel may be several years away, but we can see some light there.

JCI: How much have the initiatives to fund AIDS research and treatment in the developing world suffered in the wake of the global financial crisis?

Fauci: I don't think there's any question that these efforts are now going through a very challenging period. When [in 2004] I had the privilege of being sent by President Bush to Africa to develop what is now known as the PEPFAR program (the President's Emergency Plan for AIDS Relief), I came back and proposed what was at that time an enormous sum -15 billion dollars over five years - and we were on a roll. We were able to do things in the treatment and prevention of infection in the developing world that we never would have imagined. That has slowed down, unfortunately, because of the global financial crisis.

JCI: What do you think is the most important discovery you've made?

De Clercq: My most important discoveries have been the people - the chemists I've encountered. These include Dr. Paul Janssen, who was so passionate about global health problems. Another I could single out would be Antonin Holý, with whom I discovered the antiviral potential of the acyclic nucleoside phosphonates, the most important of which is now used for the treatment of both HIV and HBV infections.

JCI: So as a collaborator of Dr. Paul Janssen's, this award must have special meaning to you.

De Clercq: Yes, because in part it's a recognition of the work we did together. In 1986, Dr. Paul and I sat together for a meeting which lasted about eight hours, and Dr. Paul told me that his dream was to find a cure for AIDS. Our collaboration led to the identification of two leading non-nucleoside RT inhibitors. The treatments that spring from that work could really make both Dr. Paul's dream and mine come true.

\section{Kathryn Claiborn}

